\title{
MODELOS REDUZIDOS APLICADOS AO ENSINO DE GEOGRAFIA: A FORMAÇÃO DE DOLINAS E A EVOLUÇÃO DO RELEVO CÁRSTICO
}

\section{Analogue models applied to geography teaching: the sinkhole formation and the evolution of the karst relief}

\author{
Péricles Souza Lima \\ Programa de Pós-graduação em Geografia da Universidade Federal do Tocantins (UFT). Campus de \\ Porto Nacional \\ periclessouzalima@mail.uft.edu.br
}

Fernando de Morais Universidade Federal do Tocantins (UFT) Campus de Porto Nacional

\section{Recebido em 30/07/2020 \\ Aceito em 13/11/2020}

morais@uft.edu.br

RESUMO: O presente estudo constituiu simulações da formação de dolinas por meio de modelos reduzidos analógicos e buscou-se contribuir no processo de ensino-aprendizagem da educação geográfica. $O$ trabalho foi realizado usando uma caixa de madeira, adaptada com um reservatório que servira de recarga ao sistema e de um espaço destinado à superposição dos estratos sedimentares. Ao todo foram feitos 4 ensaios, que possibilitaram interpretações analíticas e didáticas. Os dois primeiros, pela natureza mais estocástica, instigam a realização de estudos futuros. Os dois últimos apresentaram feições doliniformes, tendo o terceiro chegado mais próximo do cenário natural. Por outro lado, o quarto ensaio mostrou-se mais didático. Tal ensaio foi feito com condições controladas, podendo contribuir mais para a educação geográfica nos anos iniciais, diferentemente do terceiro, propício ao ensino superior.

Palavras-chave: Dolinas; Modelos Reduzidos; Carste; Ensino-Aprendizagem.

ABSTRACT: The present study constituted simulations of the formation of dolines by using reduced analog models and it looked for contributing to the teaching-learning process of geographic education. The research was carried out using a wooden box, which was adapted with a reservoir that recharged the system, and a space for the superposition of the sedimentary layers. Altogether, four experiments were conducted, which enabled analytical and didactic interpretations. The first two, due to their stochastic nature, encourage future studies. The last two presented doliniform features, with the third coming closer to the natural scenerio. On the other hand, the fourth test was more didactic. Such a test was done under controlled conditions, and could contribute more to the geographic education in the early years, unlike the third, conducive to higher education.

Keywords: Sinkholes; Analogue Models; Karst; Teaching-Learning.

\section{INTRODUÇÃO}

O relevo cárstico é historicamente importante para a humanidade, seus recursos hídricos são fonte de abastecimento das populações há bastante tempo. Atualmente, grande parte da população mundial tem contato direto com os recursos desse sistema (TRAVASSOS; VARELA, 2008), onde a distribuição espacial das rochas carbonáticas e a tecnologia têm facilitado sua exploração em grande escala. Além do contexto hídrico, há diversos outros usos, das cavernas por exemplo (AULER; ZOGBI, 2005; 
MODELOS REDUZIDOS APLICADOS AO ENSINO DE GEOGRAFIA: A FORMAÇÃO DE DOLINAS E A EVOLUÇÃO DO RELEVO CÁRSTICO

TRAVASSOS, 2013), ou ainda a utilização das rochas carstificáveis na produção de cimento (KOHLER, 1998; TRAVASSOS; VARELA, 2008).

O relevo cárstico é instigante tanto para a comunidade científica quanto para a sociedade em geral. $O$ exocarste estabelece paisagens diferenciadas, indo dos campos de lapiás às dolinas, enquanto que as formações endocársticas, cujo contexto principal são as cavernas, possuem feições exuberantes, sendo ainda relevante para diversas espécies de animais. A diversidade de feições desse relevo depende muito dos fatores que estão correlacionados à sua gênese, sendo: regionalização climática, espessura e resistência da rocha, cobertura vegetal, quantidade de $\mathrm{CO}_{2}$ entre outros (CHRISTOFOLETTI, 1974; KOHLER, 1998).

O sistema cárstico constitui um significativo patrimônio natural. No final do século XVIII e início do XIX, o paisagista e precursor da ciência geográfica, Alexander Von Humboldt já dedicava atenção a esta geomorfologia (TRAVASSOS, 2013). Atualmente, o carste tem sido objeto de volumosas pesquisas, sejam no contexto descritivo da morfologia e dos processos de formação, na preservação da paisagem, ou ainda na busca pelo entendimento paleoclimático. Ademais, estudiosos têm contribuído com pesquisas que levam em consideração os impactos antrópicos e as alterações nas paisagens (MARRA, 2001a; MARRA, 2001b; LOBO, 2008; SILVA; MORAIS, 2016).

No estado do Tocantins, há estudos expressivos sobre áreas cársticas, sendo que o mesmo possui importantes localidades com rochas solúveis. As maiores concentrações de rochas carbonáticas deste estado encontram-se em sua região sudeste, nos municípios de Arraias, Aurora do Tocantins, Dianópolis, Taipas do Tocantins e Taguatinga (MORAIS, 2011; FERREIRA, 2015), configurando-se como uma pequena parcela do Grupo Bambuí, que possui sua maior expressão nos estados de Minas Gerais, Bahia e Goiás. Além das belezas endocársticas, a surgência do rio Azuis, curso hídrico com extensão de 137 m (FERREIRA, 2015) e com água cristalina, forma uma paisagem que atrai pessoas de várias localidades, estando, portanto, sujeito a impactos ambientais antropogênicos (SILVA; MORAIS, 2016).

Ainda que a porção sudeste seja predominante na distribuição das rochas carbonáticas do Tocantins (Figura 1), tal litologia destaca-se em outras localidades, como nas proximidades da cidade de Xambioá (MORAIS, 2011). Na região centrooeste tocantinense, as investigações têm buscado abordar a evolução geomorfológica da área da Lagoa da Confusão, recorrendo também ao estudo da vulnerabilidade dos recursos hídricos subterrâneos (PEREIRA; MORAIS, 2012; LIMA; MORAIS; PASCHOAL, 2017). Neste contexto, as dolinas vêm sendo importantes objetos de análise (MORAIS, 2017). 


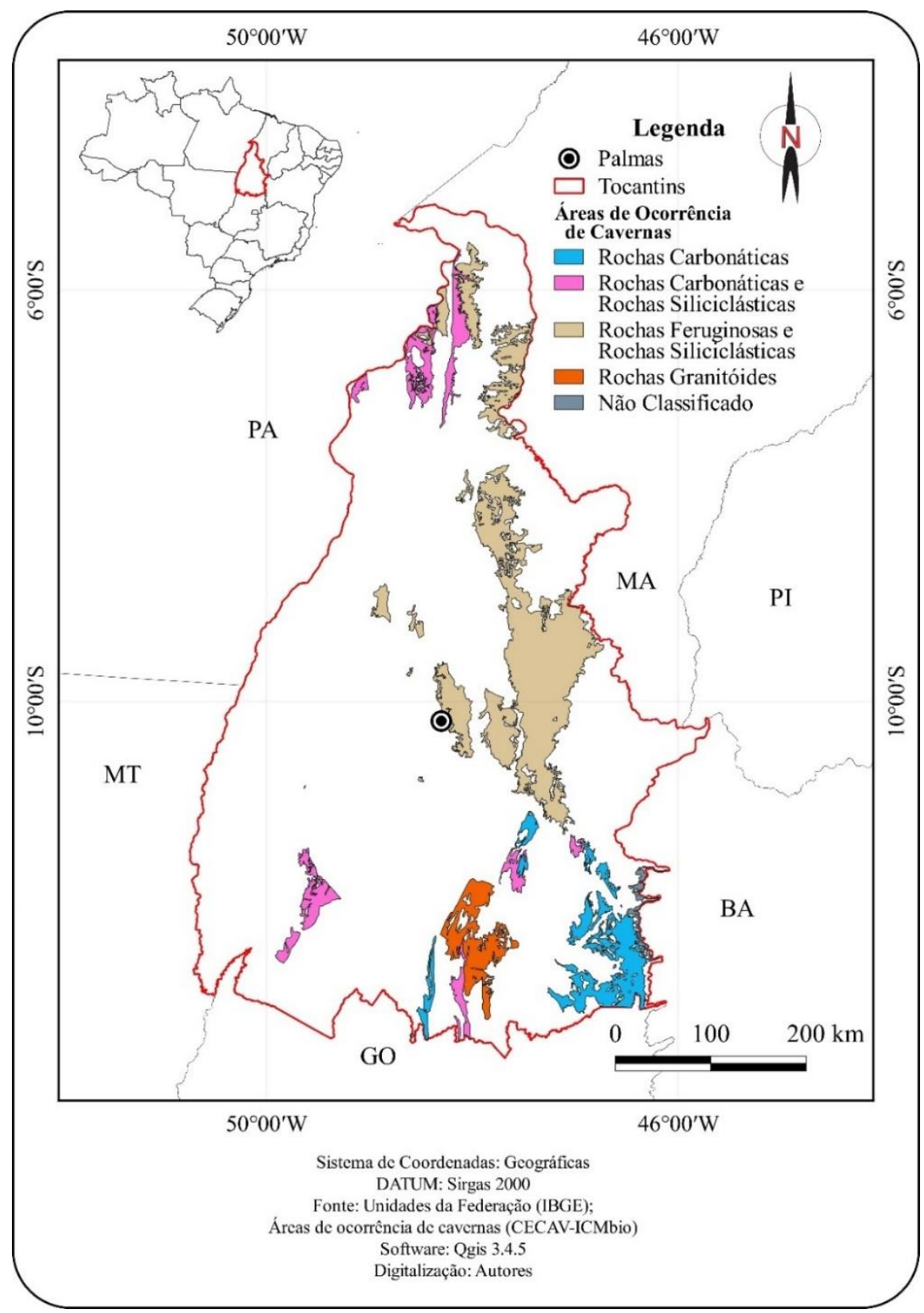

Figura 1. Áreas de ocorrência de cavernas e rochas carstificáveis no Tocantins. Fonte: Autores.

As dolinas são depressões fechadas que se formam em ambientes cársticos e que apresentam morfologias tipicamente circulares. Sauro (2003) explica que o termo dolina é usual na Europa, referindo-se à forma, já na América do Norte, é usado o termo sinkhole, relacionado à gênese. No que diz respeito à forma, podem ser classificadas como: dolinas em funil, dolinas em balde, dolinas em janela e outras (SORIANO; SIMÓN, 1993) e no que concerne à gênese: dolinas de colapso, de dissolução, de abatimento e dolinas de subsidência (PILÓ, 2000). Essas depressões podem ir de pequenas e suaves, a grandes e abruptas feições. A coalescência entre duas dolinas dá origem a uma uvala, outra feição exocárstica. 
MODELOS REDUZIDOS APLICADOS AO ENSINO DE GEOGRAFIA: A FORMAÇÃO DE DOLINAS E A EVOLUÇÃO DO RELEVO CÁRSTICO

Como importantes zonas de recarga da geomorfologia cárstica (PILÓ, 2000; MORAIS, 2017), as dolinas abarcam um amplo campo de interpretações. Suas formações estão relacionadas a vários processos e estes são dependentes de vários outros sistemas. Simón et al. (2009) afirmam que as regiões cársticas são fontes potenciais de risco em áreas urbanas, pois muitas práticas visando a expansão imobiliária negligenciam esses ambientes, contribuindo na ocorrência de problemas sociais (FURRIER; VITAL, 2011). No âmbito mais rural, o desmatamento é grande implicador no escoamento superficial e aumenta a quantidade de sedimentos carreados para essas áreas.

Desse modo, estudos sobre os ambientes cársticos devem ser cada vez mais realizados, tendo inclusive enfoques educacionais, às vezes, de cunho preservacionista, pois mesmo havendo regimentos que buscam a conservação (CONAMA 335/2003), ainda existem ações humanas que impactam esses ambientes, alterando o comportamento geossistêmico e contribuindo para a mudança da paisagem.

Dada sua importância ambiental, é necessário que a sociedade reconheça o significado dos fenômenos cársticos, bem como suas fragilidades, e que atividades potencialmente degradadoras sejam reorganizadas, a ponto de diminuírem os impactos aos recursos hídricos subterrâneos e ao carste em geral. Assim, é necessário que o homem estabeleça uma nova cultura ambiental e os conhecimentos científicos têm importante função neste processo.

Sustentado nessa perspectiva, acredita-se que a educação sobre o relevo cárstico deve ser bem abordada nos anos iniciais ( $3^{\circ}$ e $4^{\circ}$ ano) e seguir uma linearidade para a vida, fazendo valer-se não somente dos conhecimentos dos livros didáticos, mas também de atividades práticas que contribuam com uma maior assimilação dos conceitos e abordagens relacionados a essa temática, incorporando didaticamente o que Cavalcanti (1998, p.88) chama de "aprendizagem ativa do aluno", principalmente considerando os que vivem nesse tipo de relevo.

Assim, é indispensável o ensino da geomorfologia cárstica nas escolas, principalmente aquelas situadas no contexto das paisagens cársticas, sendo necessária uma explanação sobre a gênese das feições e os contextos históricos de modificações dessas paisagens, enfatizando as ações antrópicas.

Inerente à Geografia e outras ciências, o conhecimento sobre o carste, contudo, pode ser um complicador, haja vista que, em se tratando dos aspectos físicos, muitas vezes o relevo é exemplificado nas aulas, via imagens de livros, ou mesmo pela transmissão de modelos estáticos, sem a dinâmica de formação e transformação espaço-temporal, não abarcando a noção de gênese e evolução das feições (RAMON; BRUSI; BRUSI, 2015). O fato de apenas descrever os conhecimentos sem, contanto, utilizar de ferramentas que possam tornar mais simplificado o modo de entendimento dos alunos, torna o processo de aprendizagem enfadonho e dificultoso.

A utilização de técnicas que satisfaçam o desejo de aprendizagem por parte dos estudantes pode contribuir na realização de aulas melhores, com conteúdo mais completo, e ter mais a atenção voltada à aprendizagem. Experimentos que simulem a realidade de forma sistematizada podem ser de grande valia na hora de ensinar (SORIANO; SIMÓN, 1993). Ao optar pelos modelos de simulação, mesmo consciente

REVISTA GEONORTE, V.11, N.38, p.01-17, 2020.

DOI: 10.21170/geonorte.2020.V.11.N.38.01.17

(ISSN 2237 - 1419) 
MODELOS REDUZIDOS APLICADOS AO ENSINO DE GEOGRAFIA: A FORMAÇÃO DE DOLINAS E A EVOLUÇÃO DO RELEVO CÁRSTICO

da limitação que alguns podem impor, é importante que o professor esteja munido de materiais disponíveis para a realização dos procedimentos.

O uso de simulações que buscam de forma didática explicar acontecimentos ocorrentes na esfera terrestre tem sido proposto há bastante tempo, sendo usados pelos estudiosos da Grécia antiga na tentativa de desvendar o Planeta Terra (HADOT, 2006). Ademais, modelos simples vêm sendo disseminados pelos espaços educacionais (MURCIA LÓPEZ; CRESPO-BLANC, 2008), sendo importante ressaltar que o modelo criado consiga chegar o mais próximo possível da realidade (RAMON; BRUSI; BRUSI, 2015).

O relevo cárstico é um ambiente bastante retratado por meio dessa metodologia (SORIANO; SIMÓN, 1993; PUEYO ANCHUELA et al., 2016) e a formação de dolinas por meio de experimentos sistemáticos reduzidos pode contribuir para a melhoria de sua compreensão (PUEYO ANCHUELA et al., 2016), fazendo com que os alunos possam ir além da análise da feição em si, de sua gênese, mas também entenderem que a energia aplicada nessas áreas transforma todo o sistema cárstico, do encoberto ao exumado, como ocorre em várias porções do estado do Tocantins. Ter ferramentas que retratam a realidade de maneira acessível e correta é seguro ao ensino, podendo ser para os alunos fonte de inovações e incentivo à conservação, assim como, auxiliar nas análises de propagação de acontecimentos e na precaução de futuros impactos ambientais.

Tratar dessa temática no âmbito da educação é uma oportunidade de correlacionar a Geografia com outras áreas do conhecimento, abordando uma problemática relevante para o espaço geográfico e para a sociedade. Assim, a proposta apresentada almeja exemplificar como o contexto real pode ser representado, a fim de se tirar conclusões sobre o significado dos fenômenos cársticos no contexto da relação sociedadenatureza.

Nesta perspectiva, este trabalho objetivou simular a formação de dolinas a partir de modelos analógicos reduzidos, buscando demonstrar a morfogênese das dolinas, os possíveis riscos para a sociedade e a evolução do relevo como um sistema. Desse modo, procedeu-se à realização de ensaios utilizando materiais acessíveis e de baixo custo, possibilitando a discussão dos processos e formas observados durante os ensaios com a gênese e evolução das dolinas vistas na realidade. Ademais, discutiu como os modelos reduzidos analógicos podem contribuir para o ensino da Geografia nos anos iniciais do ensino fundamental, assim como no ensino superior.

\section{MATERIAIS E MÉTODOS}

Este estudo teve como ponto de partida o levantamento bibliográfico que foi dividido em três momentos: em primeiro lugar foram realizadas pesquisas sobre o relevo cárstico, principalmente a respeito das dolinas e sua importância para a sociedade, em um segundo momento, foram realizadas leituras voltadas aos estudos sobre o carste no Tocantins, e por último, concentrou-se a revisão na busca por trabalhos voltados para a utilização de modelos analógicos de laboratório em estudos de cunho tanto analítico quanto didático, especificamente na área das chamadas geociências. 
MODELOS REDUZIDOS APLICADOS AO ENSINO DE GEOGRAFIA: A FORMAÇÃO DE DOLINAS E A EVOLUÇÃO DO RELEVO CÁRSTICO

Após o levantamento bibliográfico foi construída uma caixa para a realização dos ensaios com modelos reduzidos, inicialmente, feita de isopor para ter uma ideia dimensional, a posteriori uma caixa de madeira, com as seguintes dimensões: $52 \mathrm{~cm}$ de comprimento, $27 \mathrm{~cm}$ de largura e $20 \mathrm{~cm}$ de altura. A caixa possuía um reservatório de $10 \mathrm{~cm}$ de comprimento que serviu de área de recarga para o sistema. A drenagem do lençol freático simulado se deu por meio de dois pontos de fuga (torneiras) em diferentes alturas, na extremidade oposta ao reservatório. A aplicação das cargas hidráulicas se deu por meio de pequenos furos na parede que separa o reservatório do restante da área ensaiada.

Para ter mais segurança quanto à resistência da caixa, a mesma foi revestida com massa plástica automotiva, assegurando o não vazamento de água no momento dos ensaios. A partir do momento que a massa secou, os experimentos foram iniciados, tendo como suporte para sua realização a estrutura do Laboratório de Análises GeoAmbientais. Utilizou-se uma bancada de madeira para servir de suporte à caixa, um nível de pedreiro para verificar se não havia desnível a ponto de influenciar nos resultados, um galão com uma mangueira acoplada, servindo de caixa d'água para abastecer o reservatório durante o experimento e uma régua para controlar o nível do lençol freático.

Parte dos materiais usados para fazer os estratos foi comprada (sal e gesso) e outra parte obtida no próprio campus da Universidade Federal do Tocantins (areia e cascalho). Para fazer a camada mais solúvel optou-se por gesso e areia ou sal e areia, já na cobertura superior foi usado apenas areia. Em alguns ensaios foi utilizado cascalho para facilitar o preenchimento da parte basal do modelo, onde se situa o lençol freático. Ao todo, foram realizados quatro experimentos em dias alternados para tentar gerar as dolinas.

Na primeira tentativa, o material inferior continha $4 \mathrm{~cm}$ de areia misturada com gesso, enquanto o estrato superior foi feito somente com areia fina e com espessura de $6 \mathrm{~cm}$. O segundo ensaio teve como sedimento inferior a mistura de areia e sal $(4 \mathrm{~cm})$, uma camada intermediária somente de sal $(4 \mathrm{~cm})$ e uma camada superior de areia $(4 \mathrm{~cm})$. O terceiro ensaio respeitou a mesma sequência estratigráfica do segundo ensaio, porém foi acrescentado cascalho na parte inferior. Neste ensaio, a espessura de cada camada foi de $5 \mathrm{~cm}$ de cascalho, $5 \mathrm{~cm}$ de areia misturada com sal, $3 \mathrm{~cm}$ de sal e $3 \mathrm{~cm}$ de areia.

O quarto e último ensaio teve uma camada de cascalho como base e areia fina na parte superior, tendo sido adicionadas lentes de sal em pontos específicos, visando um controle dos locais onde ocorreriam os colapsos. Ademais, neste ensaio foram colocadas miniaturas de edificações (casas e prédio) para simular os riscos que os aparatos urbanos correm quando do processo de dolinamento.

Para melhor elucidação, parte dos procedimentos metodológicos descritos encontram-se resumidos na figura 2. 
MODELOS REDUZIDOS APLICADOS AO ENSINO DE GEOGRAFIA: A FORMAÇÃO DE DOLINAS E A EVOLUÇÃO DO RELEVO CÁRSTICO

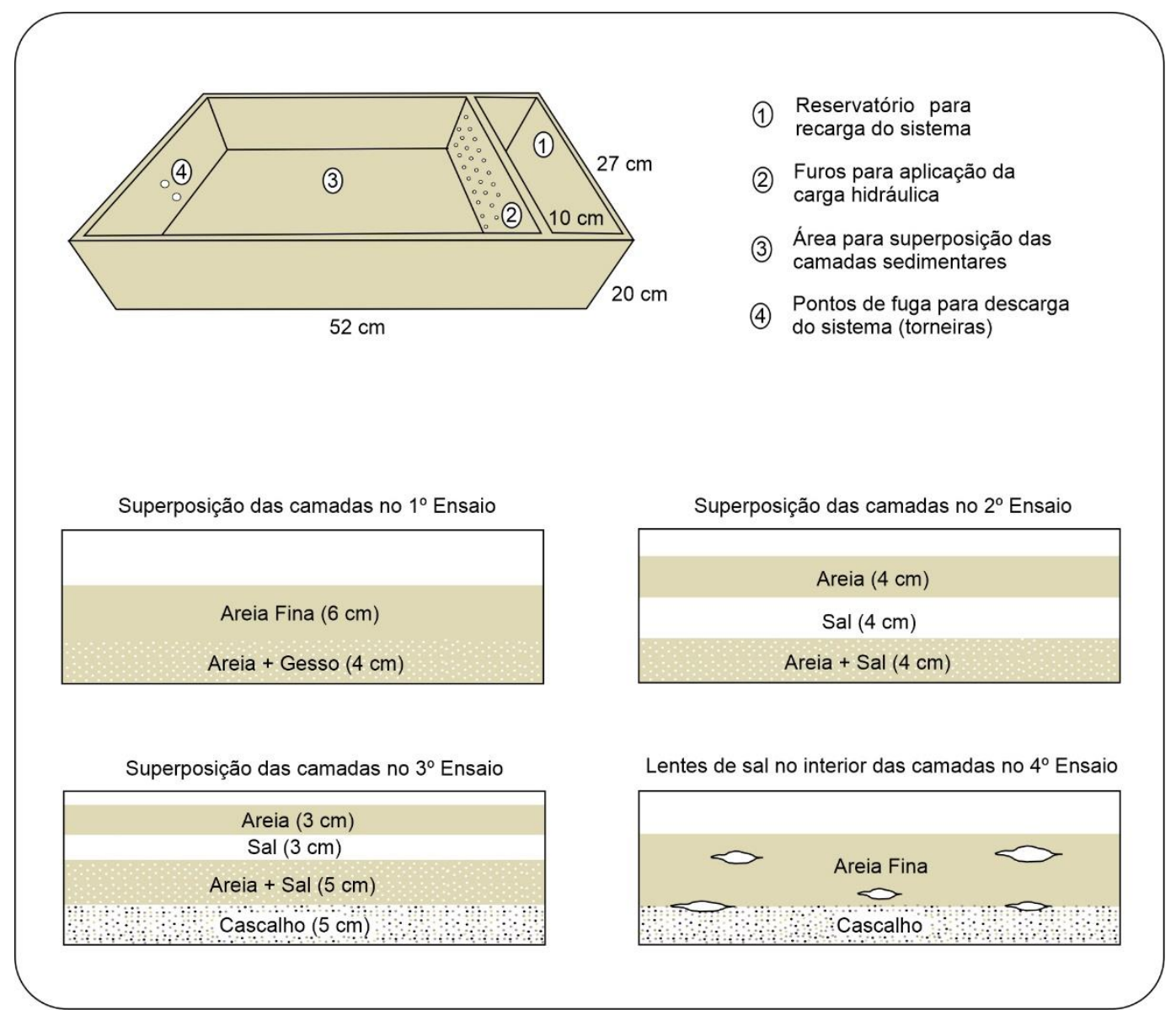

Figura 2. Modelo da caixa utilizada e configuração interna dos ensaios realizados. Fonte: Autores.

Durante os ensaios, cada estágio foi fotografado sequencialmente, sendo as imagens posteriormente analisadas e interpretadas para tirar conclusões acerca das feições geradas. Ao término, as considerações mais importantes foram organizadas de acordo com a literatura, dando suporte para redação e embasando o texto final deste trabalho.

\section{RESULTADOS E DISCUSSÕES}

O modo como os moradores locais entendem o carste pode ser um fator importante nas tomadas de decisões, contribuindo para as discussões do manejo ambiental dessas áreas. Por isso, ao tratar a temática na/para sociedade, os apontamentos devem estar muito além das belezas que esse ambiente possui. Mandu e Morais (2013), ao trabalharem sobre o tema da espeleologia nos ensinos fundamental e médio no município de Aurora do Tocantins - TO, demonstram o quão essa temática deve ser mais bem compreendida, pois, como apontam, os professores e alunos possuem pouco conhecimento sobre o sistema cárstico. 
MODELOS REDUZIDOS APLICADOS AO ENSINO DE GEOGRAFIA: A FORMAÇÃO DE DOLINAS E A EVOLUÇÃO DO RELEVO CÁRSTICO

De fato, não só as feições são relevantes na construção do saber geomorfológico, os fatores relacionados ao modo como os componentes físicos, químicos e biológicos atuam, tornam a construção do pensamento científico-geográfico do aluno um ato completo. Baseando-se nisto, o tripé (material, processos e formas), indispensável aos estudos do relevo, pode ser bem explorado nos modelos reduzidos em sala de aula.

Nesse viés, os ensaios realizados possibilitaram a formação de diversas feições doliniformes, sendo que apenas um deles não apresentou feições na superfície, mas desenvolveu cristas (lapiás) no contato da camada superior com a basal, observadas durante o processo de desmonte do experimento. De maneira geral, cada ensaio durou aproximadamente 4 horas, tendo o primeiro sido conduzido por mais de 8 horas.

O primeiro ensaio foi o que mais demorou, uma vez que não foi feito nenhum procedimento que induzisse a aceleração dos processos cársticos, além de pequena variação do lençol freático. Ao final, não foi possível observar feições em superfície. Contudo, ao desmontar o ensaio, notou-se uma "litificação" da areia com o gesso, formando um bloco com pequenas cristas, caracterizadas como lapiás (Figura 3a).

O segundo ensaio foi feito em um período de tempo quase equiparado ao primeiro. Nesta tentativa, as feições que ocorreram no modelo foram uma ruptura na superfície, caracterizando trincas de tração, e um processo de erosão por tubo, piping (Figuras $3 b$ e $3 c)$.

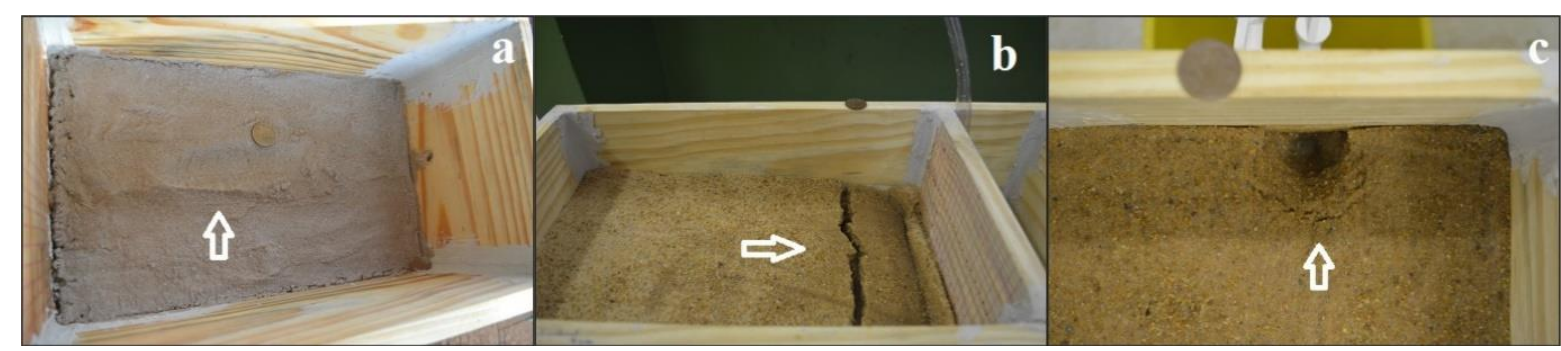

Figura 3. (a) Lapiás na areia "litificada" com o gesso; (b) Ruptura na superfície; (c) Piping. Fonte: Autores.

O terceiro ensaio apresentou feições doliniformes e demorou um pouco menos que os anteriores. O mesmo foi iniciado às 10h33min; logo aos 11 minutos iniciais ocorreram dois eventos de subsidência brusca uniforme, sem rompimento da superfície, com intervalo de 5 minutos do primeiro para o segundo. Posteriormente, ocorreu a formação repentina de uma dolina de colapso (Figura 4a), houve ainda geração de feição erosiva em tubo (piping) mais próxima do ponto de descarga do lençol freático. Em estágio mais avançado, formou-se uma dolina de subsidência que foi evoluindo gradativamente para uma dolina de colapso (Figura 4b). 
MODELOS REDUZIDOS APLICADOS AO ENSINO DE GEOGRAFIA: A FORMAÇÃO DE DOLINAS E A EVOLUÇÃO DO RELEVO CÁRSTICO

\section{$2 y=$ REVISTA GEONORTE}

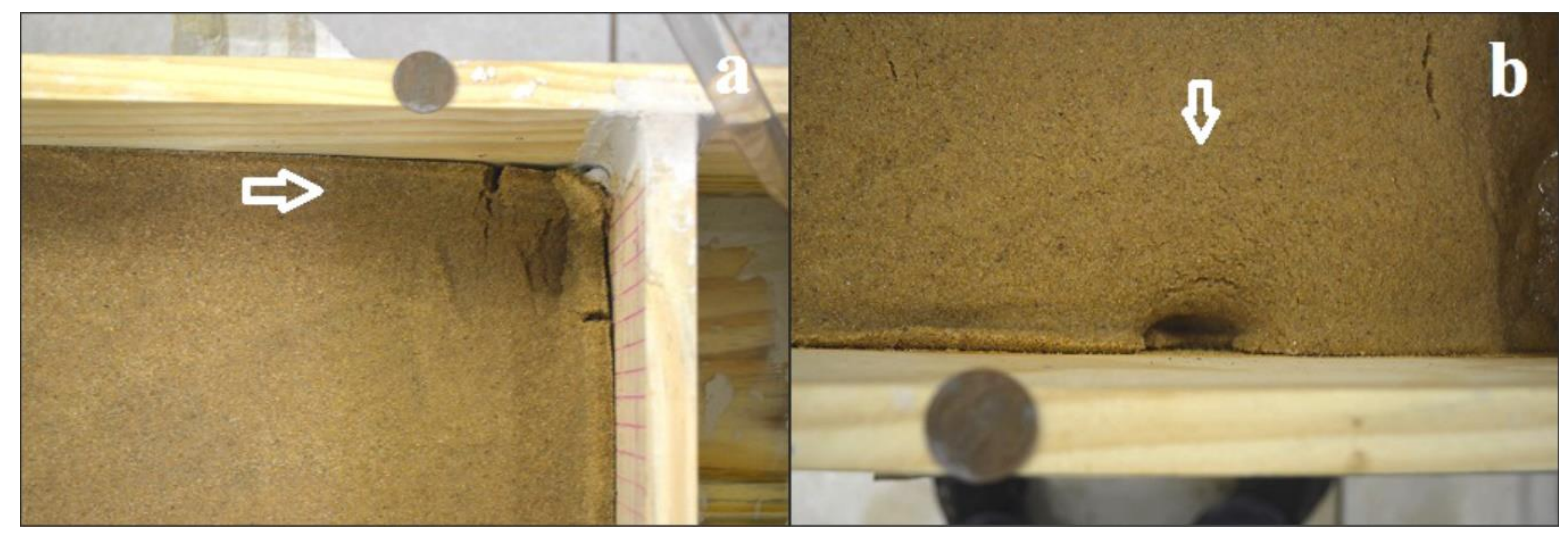

Figura 4. (a) Dolina de colapso repentina; (b) Dolina de subsidência evoluída para colapso.

Fonte: Autores.

No quarto e último ensaio 5 dolinas se formaram, três delas bem chamativas. Logo nos 5 minutos iniciais ocorreu a formação de dolinas de subsidência, com trincas de tração bem evoluídas, indicando o possível colapso em momento posterior. Depois de mais de uma hora, uma das dolinas colapsou (Figura 5a), as outras foram rebaixando cada vez mais, mas não chegaram ao ponto de colapsar (Figura 5b). Neste ensaio também aconteceu a formação de condutos. Ao finalizar o experimento, foi feito um corte em forma de perfil que demonstrou a aparência subsuperfícial de uma das dolinas (Figura 6), quando foi possível notar o desenvolvimento de uma cavidade natural subjacente à dolina, caracterizando como uma dolina gerada por processo de sufusão (GUTIÉRREZ; GUERRERO; LUCHA, 2008).

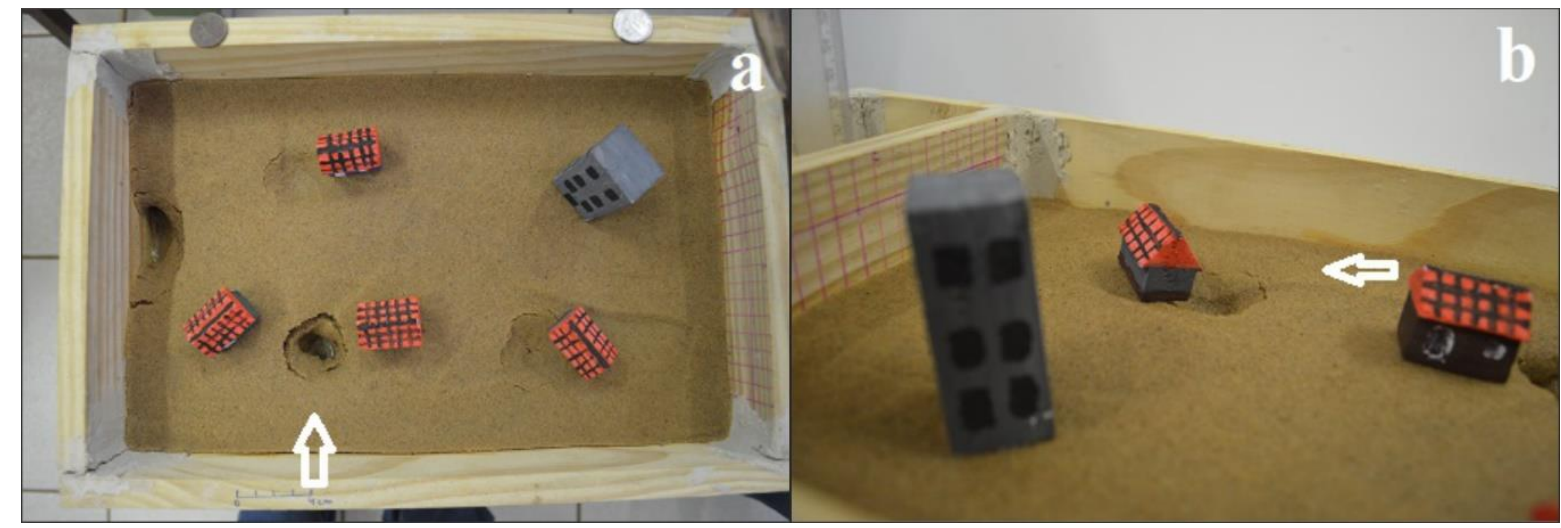

Figura 5. (a) Evolução de dolina de subsidência para colapso; (b) Dolina de subsidência.

Fonte: Autores. 
MODELOS REDUZIDOS APLICADOS AO ENSINO DE GEOGRAFIA: A FORMAÇÃO DE DOLINAS E A EVOLUÇÃO DO RELEVO CÁRSTICO

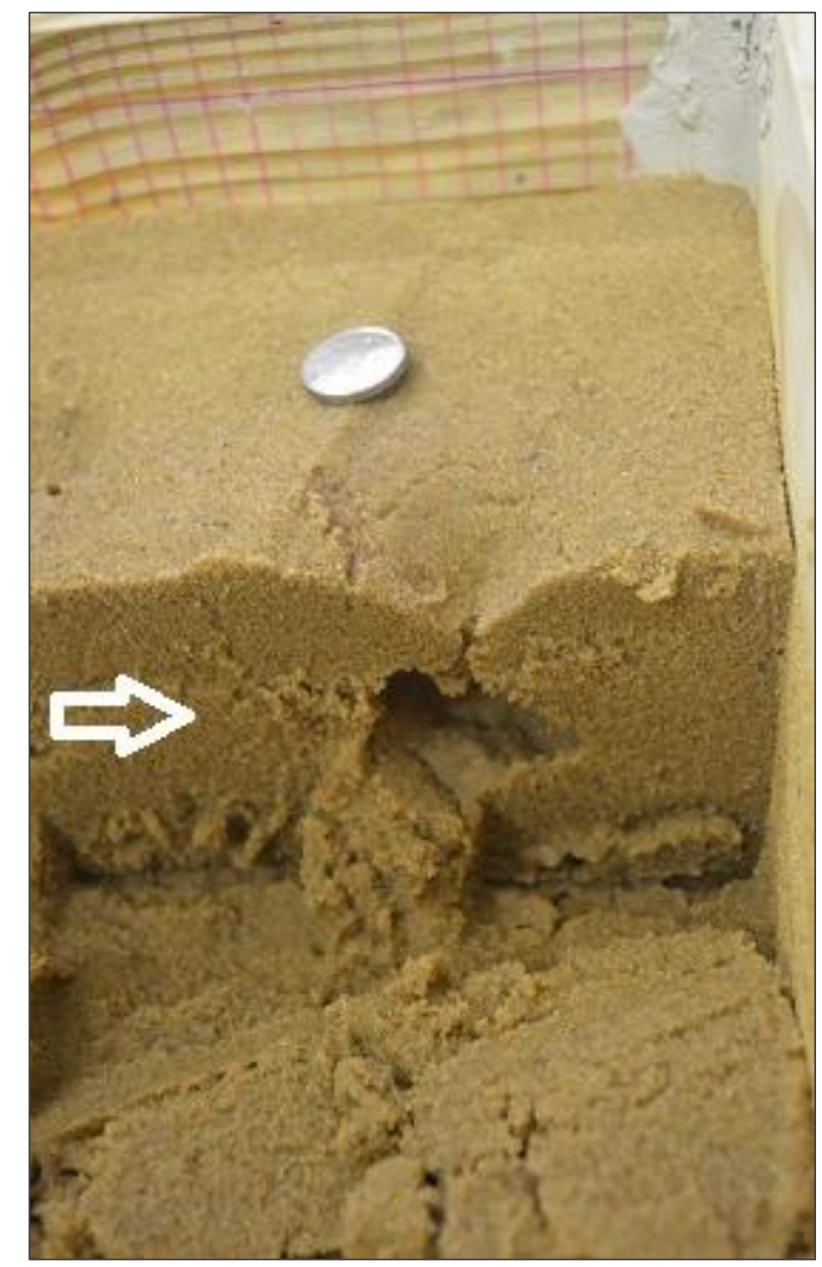

Figura 6. Cavidade subjacente à dolina, evidenciando o processo de sufusão.

Fonte: Autores.

Diante do estabelecido como proposta, de todos os ensaios, o $3^{\circ}$ foi o que mais apresentou resultados satisfatórios ao considerar a proximidade com a realidade, sendo bastante chamativo em termos analíticos quanto à gênese das feições cársticas. Em virtude de o material basal possuir granulometria maior (cascalho), o freático conseguiu estabelecer fluxos diferenciados em relação aos ensaios anteriores, tendo comportado de maneira ascendente e homogênea. Isso foi constatado logo nos minutos iniciais do ensaio. Com o lençol freático preenchido, ocorreu dissolução parcial da camada composta da mistura de areia e sal, que estava em contato com o cascalho. Tal dissolução desencadeou a subsidência repentina de todos os estratos superiores, como já citado.

Mesmo com o preenchimento do freático, aconteceu o processo de capilaridade, e a água foi tendo caminhos preferenciais perto da área de recarga. Em se tratando de estabelecer relações morfogenéticas, a dolina de colapso (Figura 4a) formada nas proximidades do reservatório pode estar associada ao soerguimento do lençol freático, quando ocorre uma ascensão das linhas equipotenciais de fluxo, contribuindo 
MODELOS REDUZIDOS APLICADOS AO ENSINO DE GEOGRAFIA: A FORMAÇÃO DE DOLINAS E A EVOLUÇÃO DO RELEVO CÁRSTICO

para maior dissolução do sal neste ponto do modelo, mesmo quando o registro de descarga (ladrão) ainda estava fechado. A camada de sal intermediária ficou mais perto do nível d'água, o que pode ter favorecido a dissolução mais intensa, ocorrendo o basculamento brusco do bloco. Benito (1987), estudando terrenos de gessos na Depressão do Ebro, Espanha, demonstra que a formação de dolina de colapso pode ser consequência do processo de dissolução do gesso que se encontra como substrato, como pôde ser corroborado pelas observações feitas no presente estudo.

Após 2h30mim do início do ensaio, optou-se pela elevação da carga hidráulica, com isso, a cobertura sedimentar perto do reservatório se desmoronou e a dolina de colapso desmanchou-se. Como o nível inicial era de $4 \mathrm{~cm}$, com a elevação passou a ser de $8 \mathrm{~cm}$. Desse momento em diante, o ponto de descarga também estava aberto, favorecendo a movimentação do freático (recarga e descarga), contribuindo para o carreamento de partículas.

Esse fator contribuiu para que se formasse uma dolina de subsidência, que progressivamente foi colapsando (Figura 4b) a partir da elevação do nível freático, quando também foi possível notar dissolução preferencial na porção lateral da caixa experimental. Fazendo uma analogia com o meio natural, esse tipo de dolina pode ter origem em áreas onde ocorrem reservatórios ou mesmo barragens, pois, em conformidade com Sallun Filho (2009) a elevação do nível d'água modifica o regime dos fluxos subterrâneos.

No que se refere à morfologia, os dados mostram que a elevação do nível da água foi mais eficiente do que o rebaixamento. $E$ que o carste representado em tal modelo analógico se caracterizou mais como um carste coberto (com delgada cobertura sedimentar) que propriamente um carste subjacente com espessa cobertura sedimentar.

No tocante aos riscos às infraestruturas urbanas e à sociedade, o experimento 4 mostrou-se mais didático, deixando as formas cársticas mais perceptíveis para os estudantes. Este último modelo já possui uma versão simplificada, disponibilizada no site do Earth Learning Idea e que foi traduzido pelo IG-Unicamp (Instituto de Geociências) como uma proposta de ensino. Mesmo assim, foi aqui trabalhado com o sentido de dar complementação aos modelos analógicos, proporcionando novas perspectivas interpretativas.

Diferentemente dos demais ensaios, esse foi induzido com a instalação de lentes de sal em localidades específicas, de modo a condicionar uma aparência final das formas que pudesse levar a considerações mais didáticas que analíticas. Assim, as feições resultantes proporcionam o entendimento de como estas depressões fechadas podem causar riscos quando não há conhecimento sobre a geologia e geomorfologia da área. Tal abordagem pode ser feita com alunos de escolas situadas em áreas cársticas, ou onde há uma demasiada exploração das águas subterrâneas, como o sudeste do Tocantins e a região de Lagoa da Confusão - TO, respectivamente.

A partir do momento em que o fluxo alcançou as lentes de sal, as mesmas foram sendo dissolvidas, gerando subsidências na sua parte superior, formando depressões suavizadas, que em seguida evoluíram para dolinas de colapso. Para facilitar a visualização das deformações em superfície, utilizou-se um borrifador para 
MODELOS REDUZIDOS APLICADOS AO ENSINO DE GEOGRAFIA: A FORMAÇÃO DE DOLINAS E A EVOLUÇÃO DO RELEVO CÁRSTICO

homogeneizar a umidade do terreno. A proximidade da dolina com as miniaturas de edificações (Figuras 5a e 5b) exemplifica o que pode acontecer, caso se construa sobre áreas de rochas solúveis sem os devidos cuidados técnicos para este tipo de terreno. Um exemplo clássico sobre isso no Brasil é o buraco de Cajamar - SP (SALLUN FILHO, 2009).

Mesmo que a morfogênese nos experimentos tenha sido por fatores ascendentes, as miniaturas de edificações possibilitam ampliar a percepção sobre a perda de estabilidade dos terrenos cársticos e consequente formação de dolinas, quando dos pesos das construções sobre estes terrenos. Tal abordagem pode ser complementada com o uso de fotografias específicas, o que torna mais inteligível o tema por parte dos alunos dos anos iniciais (DELLE ROSE; FEDERICO; PARISE, 2004; SALLUN FILHO, 2009).

Com base na BNCC - Base Nacional Comum Curricular, o quarto modelo pode ser usado no $3^{\circ}$ ano do ensino fundamental nas Unidades Temáticas: formas de representação e pensamento espacial, além de natureza, ambientes e qualidade de vida. Nestas unidades podem ser trabalhadas as habilidades que tratam, respectivamente da identificação e interpretação das imagens bidimensionais e tridimensionais em diferentes escalas cartográficas, e também a comparação dos impactos das atividades econômicas urbanas e rurais ao ambiente natural.

Tal modelo ainda pode ser trabalhado no $4^{\circ}$ ano, na Unidade Temática: natureza, ambientes e qualidade de vida. Para tanto, nesta unidade a habilidade mais propícia é a que visa identificar as características das paisagens naturais e antrópicas (relevo, cobertura vegetal, rios etc.) no ambiente de vivência dos estudantes ou mesmo o modo como o homem conserva ou degrada essas áreas.

A partir das interpretações dos fatos observados nos experimentos, e reconhecendo o caráter educacional deste trabalho, pode-se afirmar que, apesar do quarto ensaio ter mostrado dolinas morfologicamente satisfatórias e contribuir, sobretudo para o ensino fundamental 1 , o terceiro ensaio foi o mais importante, principalmente por chegar o mais próximo da realidade, tendo em vista que não foi induzido, ainda que tenha havido limitações quanto ao contexto visual. Por outro lado, os ensaios 1 e 2 tiveram resultados diferentes do esperado.

No primeiro a composição de areia e gesso virou uma espécie de "rocha", oferecendo resistência à dissolução para além do esperado. O segundo ensaio também não foi bom nos moldes planejados, pois a dissolução do sal e o carreamento de parte desse sal em direção à jusante do reservatório da caixa fez com que houvesse a ruptura de parcela da superfície.

Outra observação importante, é que nas proximidades do reservatório houve maior dissolução do sal, carecendo de novas investigações que visem a relação das linhas de fluxo ascendentes com a variação na intensidade desse processo, o que enriqueceria muito as discussões acerca da utilização de modelos para investigações hidrogeomorfológicas, que poderiam ser abordadas no ensino superior (Geografia, Geologia e Engenharias Civil e Ambiental, por exemplo). 
MODELOS REDUZIDOS APLICADOS AO ENSINO DE GEOGRAFIA: A FORMAÇÃO DE DOLINAS E A EVOLUÇÃO DO RELEVO CÁRSTICO

\section{CONSIDERAÇÕES FINAIS}

Diante dos resultados, compete dizer que os modelos reduzidos analógicos são relevantes na construção do saber, servindo de material enriquecedor do conhecimento, tanto para estudantes quanto para professores, tendo em vista que as interpretações podem se dá num plano tanto analítico, quanto didático. Assim, foi possível notar com os ensaios aqui apresentados, quando os dois primeiros não responderam ao esperado, ficando a cabo do terceiro os aspectos morfogenéticos mais condizentes com a formação de dolinas em meio natural. Por outro lado, o quarto experimento teve suas variáveis mais controladas, tendo na sua interpretação um exercício notadamente didático.

Os materiais usados na realização dos modelos reduzidos corresponderam ao esperado e foram obtidos a um custo razoável, não ultrapassando os $\mathrm{R} \$ 150,00$. A caixa de madeira foi o material com maior valor de custo, em contrapartida, o sal foi o mais barato. Os outros materiais complementares foram mais fáceis de obtenção, pois faziam parte do Laboratório de Análises Geo-Ambientais, ou mesmo encontravam-se no campus da Universidade Federal do Tocantins (areia e cascalho).

Vale ressaltar que os ensaios devem ser associados a explanações de informações conceituais e educativas acerca do relevo cárstico, de maneira a tornar as aulas de Geografia mais prazerosas. Todos os experimentos tiveram situações diferentes, e que podem ser exploradas, mas de fato, as dolinas foram visíveis apenas em dois.

$O$ fato das dolinas do terceiro ensaio terem sido esteticamente menos exuberante, não descarta a funcionalidade analítica do modelo, e a realidade mostra-se mais próxima neste experimento, podendo este ser mais bem aproveitado no ensino superior como complementação na formação dos professores de Geografia, possibilitando um melhor entendimento dos processos atuantes na transformação da paisagem cárstica. Já as dolinas induzidas têm a capacidade de dar subsídios para outras discussões, como a própria formação das cavernas, pois, a partir do momento que se fez um perfil, foi verificada a formação interna de vazios, ou seja, uma "protocaverna".

Para além das feições doliniformes e das interpretações sobre a gênese das cavernas, o quarto ensaio possibilita demonstrar e discutir a influência das ações antrópicas na transformação da paisagem e como os edifícios construídos sobre relevos cársticos podem estar em risco, correspondendo ao proposto pela BNCC no que se refere aos anos iniciais do ensino fundamental ( $3^{\circ}$ e $4^{\circ}$ ano).

Os ensaios que supostamente não corresponderam ao esperado (1 e 2), ou seja, não desenvolveram dolinas, podem ser melhor trabalhados e gerar informações para o estudo do sistema cárstico, sobretudo a respeito de outras morfologias de notável interesse educacional.

Entretanto, os modelos de dolinas ainda têm muito a evoluir e podem partir não somente da ação do lençol freático como agente geomorfológico, mas também da atuação de fluxos verticalmente descendentes, representando modelos epigenéticos de formação de cavernas. Para fins de atividade em sala de aula, esse caminho, de

REVISTA GEONORTE, V.11, N.38, p.01-17, 2020.

DOI: 10.21170/geonorte.2020.V.11.N.38.01.17

(ISSN 2237 - 1419) 
MODELOS REDUZIDOS APLICADOS AO ENSINO DE GEOGRAFIA: A FORMAÇÃO DE DOLINAS E A EVOLUÇÃO DO RELEVO CÁRSTICO

fato, pode ser um complicador em termos de tempo ou até de materiais, devendo ser considerado a construção de um modelo analógico em laboratório, onde possa ser analisado pelos estudantes apenas a dinâmica morfogenética em si, deixando a parte operacional de confecção do modelo reduzido para o professor. Destarte, isso é algo que pode dar novos horizontes na compreensão dos ambientes cársticos.

Por fim, considerando a ocorrência das dolinas, o terceiro ensaio pode ser aplicado durante uma atividade laboratorial em ambiente universitário, pois o tempo foi considerável, sendo necessário mais de 4 horas de ensaio, possibilitando várias interpretações analíticas. O quarto ensaio, ao ser trabalhado em ambiente escolar pode ser feito em sala de aula ou durante uma feira de ciências, tendo em vista que, ao utilizar as lentes de sal para induzir o experimento, as feições rapidamente se formam.

\section{AGRADECIMENTO}

O desenvolvimento desta pesquisa contou com benefícios do Programa Institucional de Produtividade em Pesquisa da UFT (PROPESQ/UFT), Edital 10/2018.

\section{REFERÊNCIAS}

AULER, A.; ZOGBI, L. Espeleologia: noções básicas. São Paulo: Redespeleo Brasil, 2005.

BENITO, G. Karstificacion e colapsos karsticos en los yesos del sector central de La Depresión del Ebro (Aragon, España). Cuaternario y Geomorfologia, Ávila - Espanha, v. 1, p. 61-76, 1987.

BRASIL. Ministério do Meio Ambiente. Conselho Nacional do Meio Ambiente. Resolução $n^{\circ} 335$, de 3 de abril de 2003. Dispõe sobre licenciamento ambiental de cemitérios. Diário Oficial da União: Seção 1, Brasília, DF, n. 101, p. 98-99, 28 maio. 2003. Disponível em: http://www.mma.gov.br/port/conama/res/res03/res33503.xml. Acesso em: 26 abr. 2018.

BRASIL. Ministério do Meio Ambiente. Ministério da Educação. Base Nacional Comum Curricular - BNCC. 2 ${ }^{\text {a }}$ versão, Brasília - DF, 2017. Disponível em: http://portal.mec.gov.br/index.php?option=com docman\&view=download\&alias=7961 1-anexo-texto-bncc-aprovado-em-15-12-17-pdf\&category slug=dezembro-2017pdf\&ltemid=30192. Acesso em: 20 maio. 2018.

CAVALCANTI, L. S. Geografia, escola e construção do conhecimento. Campinas: Papirus, 1998.

CHRISTOFOLETTI, A. Geomorfologia. São Paulo: Edgard Blücher, 1974. 
MODELOS REDUZIDOS APLICADOS AO ENSINO DE GEOGRAFIA: A FORMAÇÃO DE DOLINAS E A EVOLUÇÃO DO RELEVO CÁRSTICO

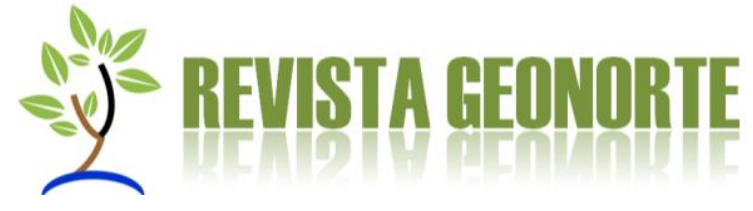

DELLE ROSE, M.; FEDERICO, A.; PARISE, M. Sinkhole genesis and evolution in Apulia, and their interrelations with the anthropogenic environment. Natural Hazards and Earth System Sciences, v. 4, n. 5/6, p. 747-755, 2004.

FERREIRA, Z. A. Diagnóstico físico-conservacionista do ambiente cárstico da bacia do córrego Cana-brava, Aurora do Tocantins - TO. Orientador: Fernando de Morais. 2015. 164 f. Dissertação (Mestrado em Ciências do Ambiente) - Universidade Federal do Tocantins, Palmas - TO, 2015.

FURRIER, M.; VITAL, S. R. de O. A formação de dolinas em áreas urbanas: o caso do Bairro de Cruz das Armas em João Pessoa - PB. Revista Brasileira de Geografia Física, Recife - PE, v.1, p.161-173, 2011.

GUTIÉRREZ, F.; GERRERO, J.; LUCHA, P. A genetic classification of sinkholes illustrated from evaporite paleokarst exposures in Spain. Environmental Geology. v. 53, n. 5, p. 993-1006, 2008.

HADOT, P. O véu de Ísis: ensaio sobre a história da ideia de natureza. Tradução, Mariana Sérvulo. São Paulo: Edições Loyola, 2006. p. 230-231.

KOHLER, H. C. Geomorfologia cárstica. In: GERRA, A. J. T.; CUNHA, S. B. (org.). Geomorfologia: uma atualização de bases e conceitos. 3. ed. Rio de Janeiro: Bertrand Brasil, 1998. p. 309-334.

LIMA, P. S.; MORAIS, F.; PASCHOAL, L. G. Estudo da variabilidade espacial da condutividade hidráulica do entorno da Lagoa da Confusão - TO. In: SIMPÓSIO BRASILEIRO DE GEOGRAFIA FÍSICA APLICADA, 17., 2017, Campinas - SP: Anais

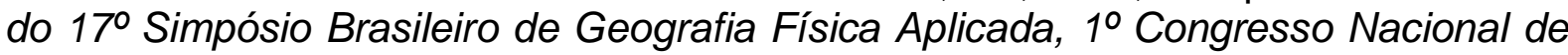
Geografia Física. Campinas - SP: Instituto de Geociências - Unicamp, 2017. p. 2230. Disponível em: https://ocs.ige.unicamp.br/ojs/sbgfa/issue/view/75. Acesso em: 26 abr. 2018.

LOBO, H, A. S, Capacidade de Carga Real (CCR) da Caverna de Santana, Parque Estadual Turístico do Alto Ribeira (PETAR) - SP e Indicações Para o Seu Manejo Turístico. UNESP, Geociências, São Paulo - SP, v. 27, n. 3, p. 369 - 385. 2008.

MANDU, S. A.; MORAIS, F. Abordagem espeleológica no ensino fundamental e médio no município de Aurora do Tocantins - TO. In: CONGRESSO BRASILEIRO DE ESPELEOLOGIA, 32., 2013, Barreiras - BA. Anais do 32ํㅡㄹ Congresso Brasileiro de Espeleologia. Campinas - SP: SBE - Sociedade Brasileira de Espeleologia, 2013. p. 149-155. Disponível em: http://www.cavernas.org.br/32cbeanais.asp Acesso em: 26 abr. 2018.

MARRA, R. J. C. Espeleo Turismo: planejamento e manejo de cavernas. Brasília: Editora WD Ambiental, 2001a. 
MODELOS REDUZIDOS APLICADOS AO ENSINO DE GEOGRAFIA: A FORMAÇÃO DE DOLINAS E A EVOLUÇÃO DO RELEVO CÁRSTICO

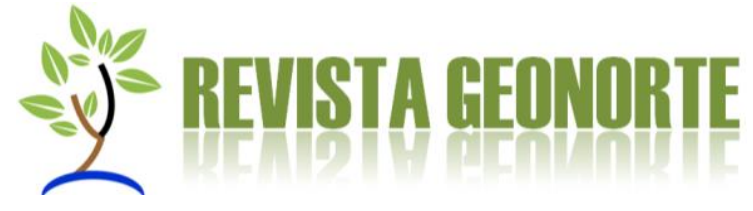

MARRA, R. J. C. Planejamento e a Prática do Turismo em Cavernas. In: CONGRESSO BRASILEIRO DE ESPELEOLOGIA, 26., 2001, Brasília - DF. Anais do $13^{\circ}$ Congresso Internacional de Espeleologia, 4 Congresso Espeleológico da América Latina e Caribe, 26ํㅡㄴ Congresso Brasileiro de Espeleologia. Campinas - SP: SBE Sociedade Brasileira de Espeleologia, 2001b. p. 663-666. Disponível em: http://www.cavernas.org.br/anais26cbe/26CBE 663-666.pdf. Acesso em: 26 abr. 2018.

MORAIS, F. Classificação morfológica das dolinas da região de Lagoa da Confusão TO. In: CONGRESSO BRASILEIRO DE ESPELEOLOGIA, 34., 2017, Ouro Preto MG. Anais do 34ํㅡㄹ Congresso Brasileiro de Espeleologia. Campinas - SP: SBE Sociedade Brasileira de Espeleologia, 2017. p.283-287. Disponível em: http://www.cavernas.org.br/anais34cbe/34cbe 283-287.pdf. Acesso em: 26 abr. 2018.

MORAIS, F. Panorama da Espeleologia no Estado do Tocantins. In: MORAIS, F. (org.). Contribuição à Geografia Física do Estado do Tocantins. Goiânia: Kelps, 2011. p. $87-112$

MURCIA LÓPEZ, M.; CRESPO-BLANC, A. La formacíon de oceanos y cadenas de montanas a partir de modelos analógicos: maquetas y nuevos materiales. Enseñanza De Las Ciencias De La Tierra, Girona - Espanha, v. 16, n. 2, p. 173 - 177, 2008.

PEREIRA, G. C.; MORAIS, F. Geofísica aplicada ao estudo dos fluxos subsuperficiais no entorno da Lagoa da Confusão - TO. Revista Geonorte, Edição Especial, Manaus - AM, v.2, n.4, p.1475-1483, 2012.

PILÓ, L. B. Geomorfologia Cárstica. Revista Brasileira de Geomorfologia, Brasília DF, v. 1, n. 1, p. $88-102,2000$.

PUEYO ANCHUELA, Ó. et al. Generación de dolinas en medios aluviales con modelos analógicos. Enseñanza De Las Ciencias De La Tierra, Girona - Espanha, v. 24, n. 1, p. $96-106,2016$.

RAMON, L.; BRUSI, S.; BRUSI, D. Erupciones en el laboratorio. Modelos analógicos de peligros volcánicos. Enseñanza De Las Ciencias De La Tierra, Girona - Espanha, v. 23, n. 1, p. $96-106,2015$.

SALLUN FILHO, W. Subsidência e colapso em terrenos cársticos. In: TOMINAGA, L. K.; SANTORO, J.; AMARAL, R. (org.). Desastres naturais: conhecer para prevenir. São Paulo: Instituto Geológico, 2009. Cap. 7.

SAURO, U. Dolines and Sinkholes: aspects of evolution and problems of classification. Acta Carsologica. Postojna - Eslovênia, v. 32, n. 2, p. 41-52, 2003. 
MODELOS REDUZIDOS APLICADOS AO ENSINO DE GEOGRAFIA: A FORMAÇÃO DE DOLINAS E A EVOLUÇÃO DO RELEVO CÁRSTICO

SILVA, F. F.; MORAIS, F. Índice de perturbações ambientais em áreas cársticas do estado do Tocantins - primeira aplicação no Brasil. Revista Brasileira de Geografia Física, Recife - PE, v. 9, n. 3, p. 766-777, 2016.

SIMÓN, J. L. et al. Riesgo de subsidência kárstica en áreas urbanas: el caso de Zaragoza. Enseñanza De Las Ciencias De La Tierra, Girona - Espanha, v. 17, n. 3, p. 303-315, 2009.

SORIANO, M. A.; SIMÓN, J. L. Modelo a escala reduzida del desarrollo de dolinas aluviales. Enseñanza De Las Ciencias De La Tierra, Girona - Espanha, v. 1, n. 3, p. 201-203, 1993.

TRAVASSOS, L. E. P. O carste e as cavernas nas obras de Alexander Von Humboldt. Biblio 3W. Revista Bibliográfica de Geografía y Ciencias Sociales, Barcelona Espanha, v. 18, n. 1034, 2013. Disponível em: http://www.ub.edu/geocrit/b3w1034.htm. Acesso em: 26 abr. 2018.

TRAVASSOS, L. E. P.; VARELA, I. D. Aspectos legais do uso da água em regiões cársticas. OLAM - Ciência \& Tecnologia, Rio Claro - SP, v. 8, n. 3, p. 386-400, 2008. 